\title{
Role of GIS in Crime Mapping \& Analysis
}

\author{
Iqra Shafique ${ }^{1}$, Syeda Ambreen Zahra ${ }^{1}$, Tuba Farid ${ }^{1}$, Madiha Sharif ${ }^{1}$
}

\begin{abstract}
In most recent years, crime analysis has turned into a broad- spectrum term that needs a considerable measure of research on crime investigation and crime mapping. Study about crime with respect to its spatial and temporal distribution is important because data about crime incident is one of the most urgent need to fight against crime. Crime mapping and analysis play an integral role in essentially advanced form of crime representation, visualization and respond satisfactorily to the problem of criminality. It also lets the analysts to figure out how crimes are spread evenly over the zone. GIS plays an effective role in mapping of crime. This paper puts on the diverse utilities of GIS to recognize the hotspots in addition to encourage the advancement of investigation inclination strategy for policing. The functional approach in the present investigation for crime mapping can be successfully applied for improvement of user-interfaces stage for the advancement of safe city strategies.
\end{abstract}

Keywords: Crime mapping, Spatial, GIS, Hotspot, Spatial Temporal analysis, RTM, Reggresion, Correlation, GAM, GEM.

\section{Introduction}

For the last few years, a new worldwide social order leads to the growing ratio on the criminal activities and raises the need to investigate latest methods to deal with information about criminality. (Jorge Ferreira, et al, 2012). Crime mapping and spatial analysis of crimes are acknowledged as strong methods for the learning and control of crime because crime maps help one to investigate crime data and enhanced perceptive not only why a crime raises, but where it is taking place.(Gupta, Rajitha, et al, 2012).

"Hurtful work or need against the masses as the State needs in similarity with stop yet which, above conviction, is culpable by means of fine, detainment, as well as death. No organization constitutes a crime unless it is pronounced pecan inside the lawful rules on the nation. Crime is unlawful attempt up to desire is denied by method for the law. Blame is habitually called an 'offense'. A few people put on shirts so much discourse 'it's exclusively unlawful if ye reach got'.'[34]

Straightforward maps, as show the areas the place of violations or centralizations of wrong doings hold came to fruition perform keep matured as per assist endorse watches in similarity with areas those are generally required. Approach producers inside police divisions may utilize more convoluted maps in congruity with inspect patterns among criminal movement, and maps may also demonstrate importance between settling destructive cases.

For instance, analysts can likewise utilize maps as per better catch the looking examples on progressive hoodlums then as per speculate the place this guilty parties may live. Utilizing maps so help people envision the geographic parts on wrongdoing, be that as it may, is presently not limited as per law requirement. Mapping is capable outfit particular records with respect to blame or criminal conduct in impersonation of lawmakers, the press, yet the general open.

Crime mapping answer three main subprograms within crime investigation.

- It uses visual and statistical analyses of the spatial conducting crimes and other types of actions.

${ }^{1}$ CS \& IT, University of Lahore, Gujrat, Pakistan

Corresponding email: Msit.5504@gmail.com 
- It allows analysts to associate spatial and non-spatial data.

- It furnishes maps that are helped to put across analysis results.

\section{Crime Mapping Today}

Colleague effect neither provides careful, true and adequate matter not far from protect nor does it help in development goals and decision support. Spatial data analysis help one investigates crime data and enhanced perceptive not only why a crime rises, but where is taking place. . (Gupta, Rajitha, et al, 2012).

An acronym in light of Geographic records Systems that alludes after current portable workstation transcription up to desire catches, records, stores and examinations information regarding utilizations of earth's floor (James, O. 2014). It is additionally portrayed by method for paying for actualities alluding to as indicated by applications and in that place areas of floor surface sure as roadway, video show units exercises as much she happen, recovery or show of uncommon information, as pleasantly as mapping.

It additionally involves geographic profiling the place areas are carefully entered by method for address, GIS thrived along the upward push concerning automated pc mechanical insurgency or has subsequently some separation measured as per remain completely phenomenal into settling many entangled social, monetary then politic inconveniences of humankind. Effectively, such has settled much injustice issues in the predominant world.

\subsection{Getting Guilt to a Map}

It is nonetheless workable in imitation of leading easy offense mapping through occupying pins between maps; alternatively crimes facts (both entire into entire or exclusively) contain a multiplicity on spatialtransient data.

Unless the records are mechanized then examined utilizing fitting programming, substantial tests also, clear procedures, so statistics intention remain usually inaccessible to both specialists also, professionals. The excellent programming arrangements are usually eluded in accordance with so geographic information frameworks, or GIS. GIS maintain spatial data of 3 essential ways: records are eking out away namely focuses, traces then polygons.

While spatial data are last as like focuses, traces and polygons, characteristic records are critical proviso the spatial records is in accordance with hold extra than shallow honor crimes records are mapped by a procedure called Geocoding. (Jerry Ratcliffe, 2010).

Geographic statistics frameworks (GISs) improve PCs in conformity with speak according to and observe spatially associated wonder. All GISs bear twin functions:

(i) To show maps then geographic components, because example, obliqueness locations (focuses), streams (lines), yet assessment tracts (polygons)

(ii) To utilize a database supervisor so arranges and relates faith facts to specific information highlights.

A GIS uses an advanced information database in conformity with interface spatial records in accordance with wise data. Several varieties over coordinating calculations possess a GIS in imitation of connect then preserve upon spatial connections amongst geographic yet enlightening data. The potential according to interface or keep above spatial connections among statistics units characterizes a GIS. (Philip R. Canter). The uncovering was undiminished close to handsome after goals

- To pick out warm spots as nicely as much using army because of specific sorts on crime.

- To help police in conformity with take strong measures kind of expanse regarding legion in area Inclined according to crime.

- To build over a methodological law because of wrongdoing mapping making use of GIS. 


\section{Geographical Information System and Crime Mapping}

GIS plays an essential role in crime mapping and analysis. The ability to contact and proceed information quickly, whereas displaying it in a spatial and visual means allows agencies to deal out assets rapidly and more successfully. The mainly dominant beat in law enforcement is information technology. Geographical information system is an information system that describes the objects with location.

A geographical information system converts physical elements of the real world such as roads, rivers, mountains, buildings into forms that can be visualized and analyzed, such as banking system, climate system, oceans, traffic, educational system police information about crimes,. GIS utilizing two sorts of information model vector and raster information. Vector deal with the discrete objects and raster deal the continuous objects. Both vector and raster are not the same as every other. (Paulo Joao, et al, 2012).

After collection, edition and approving this data spatial analysis permits the assessment of these attributes and with the following space, it gives a geographical value to any geographical wonders. The usage of geographic data framework for wrongdoing mapping maps, envision and analyze crime hot spots along with other vogues and forms. It is a basic constitute of offence judgment and the protect deposit. A GIS applies pair types of make to suggest objects and locations in the real world. (Jose Martin, et al, 2012) These are denoted to as polygon, point, line and image features.

The spatial data may be the location. GIS not only permits consolidation and spatial analysis of the data to discover, capture and indict mistrust, but it also helps more positive measures in the course of helpful allowance of resources and better policy setting. In the next section of the paper we provide a framework of crime mapping that include background, methodologies and conclusion.

\section{Background}

Crime mapping has long been the fundamental past of crime analysis today. The use of maps in criminology has its shadow back to at least years 1900. Most up-to-date nations have moved from the "pin on maps" to the use of GIS. Sorrowfully, many developed nations are still using outdated file system and installing analog. Several times police operations are brought on the simple "trial and error". Moreover when the crimes are committed the outdated systems were useful to point out but they also had a noticeable constriction because the preliminary crime figure was missing in latest version. The analog maps were not child's play. Additionally, when certain kinds of crimes are shown by pins of different colors which are mingled in map are difficult to understand. Pin maps have short comings i.e. space, wastage of time and lacking the ability of evolving a logical national database. Having these shortcomings in existing system, it is the demand of time to research in better way regarding criminology. Therefore, efforts have been made to move on GIS. [22]

\section{Literature Review}

Till our study for this proposal shows that despite the advancement in the technological field still outdated methods are being used for mapping and tracking the crime in the society. This practice of outdated methods produces a major gap between the response from police or action bodies and the criminals. This happens due to the use of slow method (i.e. pin maps) to detect the crime location (Toju Francis balogun, 2016). The outdated method makes a huge waste of manpower and time resources, and produces frustration in the police department. Hence the latest technology like Geographical Information System (GIS) must be used to map and detect the crime location in order to make quick response to the crimes. (Pukhtoon Yar, 2016)

\section{Overview of Methdologies}

After reviewing several papers, we have summarized different methodologies that help 
Authors to understand spatial analysis of crime.

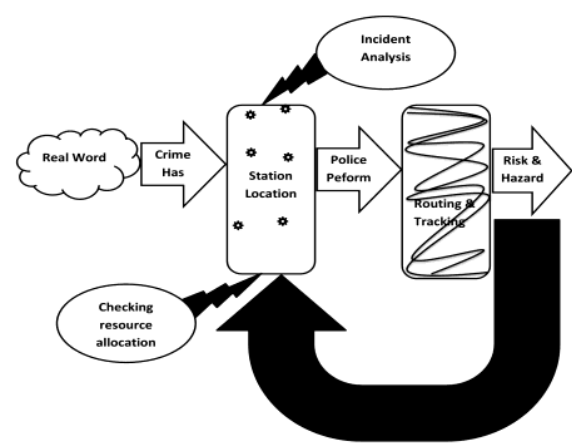

Figure1 Crime Mapping Scenario

Figure 1: Survey based analysis

1. Survey based analysis

To effectively understand the nature and location of criminal activities, a reliable data is necessary. For this purpose criminologists have developed two methods for obtaining information on the extent and pattern of crime and victimization in society

- Crime Survey

- Victim Survey

After understanding the spatial patterns associated with crime and victims in the area, the criminologists can determine the origin of criminal activities in the zone and made possible solutions of the problems. [1]

2. (Balogun et al, 2014) proposed a "questionnaire method" to obtain information from police and the general public. Studies reveals that people have no confidence on police. Due to the outdated resources and methods, police departments are restricted in reducing crime. But by utilizing GIS resources, crime analysists can create:

- Digital land use maps for showing crime location

- Crime Geo-spatial database to reduce redundancy of records

- Spatial analysis for processing spatial queries
GIS can provide both printed and soft copy navigated maps to help analyzing crime incidents planted on their location, type or proceeding time.

\section{Identifying Hotspots}

Hotspot technique is basically used to identify areas where crime levels are high. The Hotspot analysis tool identifies spatial clusters of statistically significant high or low value attributes. Different methods for hotspot detection are as follows:

- Spatial analysis method:

This method checks the location, attributes and connection of features in spatial data among overly and other technical techniques.

- Interpolation Method:

This process used to predict values at alternate unknown points

- Mapping cluster:

Also known as spatial Autocorrelation. This process used an amount of degree to which a set of spatial features and the data values are associated with it. [4]

4. According to (Shahebaz m Ansari, 2014), hotspot consists of the following Six steps:

Data collection is the basic step of implementation. After data collection Georeferencing of dataset takes place. Then spatial features are digitized. Then police station and their boundaries are mapped. After that crime data base is created and the hotspot method is applied on the data set and in the end result and analysis are done.

\section{Risk Terrain Model (RTM)}

RTM displays a map that describe the spatial properties of land [11]. In RTM, separate map layers are created, that represents the spatial phenomena of a land with GIS. Then thematic layers are joined to produce a blended risk terrain map with values that demonstrate the spatial impact of all features at every place throughout the landscape. RTM not only identify the hotspot areas but also it explains the "Spatial patterns"

Sukkur IBA Journal of Computing and Mathematical Sciences - SJCMS | Volume 1 No. 2 July - December (C) 2017 Sukkur IBA University 
that are associated with crime and offer possible solutions to overcome risk factors.

The disadvantage of RTM is that, "it do not create obsolete scenarios where crime will occur" [11]

6. According to (Yar \& Nasir, 2016), there is "relationship between crime and weather". Most crime occur in summer season because weather effects on the mentality of a man. To prove this, the data should be collected from both internal and external resources. The collected data was evaluated by the following criterion:

- Police station wise circulation of crime

- Crime committed on the basis of weather

- Determination of hotspots

Analysis shows that when weather gets hot, people became mad and loss their temper.

7. Newer Technologies:

To address the changing circumstances in crime, Law enforcement agencies find out new technologies to reduce crime. These are described below:

- From Feet to the ground to data:

To check where there is a need to open a new police department

- From guts to analytics:

Departments rely on professional resources that can present a new geographical way to produce meaningful impact.

- From reaction to anticipation:

In the past, police departments reacted to crime by responding when something happened. Through the use of information and analytics, a more proactive approached can be embraced in which issues are identified and resources are utilized to prevent criminal activity throughout the community. This requires three analytical techniques:

- Identifying Hot spots

To figure out where crime levels are high and where crimes are occurring frequently
- Correlation

When attempting to comprehend crime through GIS, it is critical to analyze how two separate components are connected. Correlation demonstrates the association between components on land.

\section{- Regression}

Shows the corporation between variables. It is a method that locates the regular connection among attributes. (Corporal \& Beaty, 2013)

\section{ArcGis}

Software that provide us the facility to generate Maps. [8] To perform analysis on spatial data, manage large amount of spatial data and produce cartographically appealing maps that help us in decision making, ArcGis will give one common platform to meet your GIS needs.

9. There are two ways to automate the geographical analysis of crime:

- GAM (Geographic Analysis Machine)

Demonstrate that without having detailed statistical and geographic knowledge, we can analyze the crime hotspots areas and draw patterns of crime on map that are found in that particular area.

\section{- GEM (Geographic Explanation Machine)}

Demonstrate that after getting information from GAM, we can investigate crime data. GEM explain the geographic variables on ground so that it can fully support the crime analysts to deal with the hotspots found. [9]

\section{Sensor technologies}

To investigate crime, GIS depend on "Sensor Technologies" (Umer Shehu, 2015). In GIS a technology, named as SPAGHETTI can be used for map digitizing. For crime detection, this technique comprise with Ariel Sensor technologies that identifies objects on earth. It additionally includes geographic graphs in which areas are digitally entered by address, interpret with calculation that

Sukkur IBA Journal of Computing and Mathematical Sciences - SJCMS | Volume 1 No. 2 July - December @ 2017 Sukkur IBA University 
delivers a likelihood surface indicating the possibility where crime incidents are high.

\section{Study Area}

The crimes data were collected from the Faisalabad City Police Department. There are forty police stations in the Faisalabad district, and 18 police stations fall within the study area. The paper based crime reports were used for marking the crime events. The law enforcement agencies in Pakistan fall behind in using the modern technology and the electronic crime recording is not in practice. Since there was no standardized crime reporting system, we had to digitize the paper based crime reports and mark the crime incidents on google maps. The crime reports of 2015 and 2016 were geocoded with the XY locations.. Only the network constrained crime events were included in the analysis. House robberies, burglaries, crimes against persons, and other petty crimes are not part of this analysis. A total number of 2059 crime events in 2015 and 2016 were geocoded. The points were snapped to the lines by using the RTW tools for ArcGIS developed by Wilson (2012).

\section{Geo Referencing of the Dataset}

Raster data is commonly obtained by scanning maps or collecting aerial photographs and satellite images. Thus, to use some raster datasets in conjunction with our other spatial data, we may need to align or geo reference them to a map coordinate system.

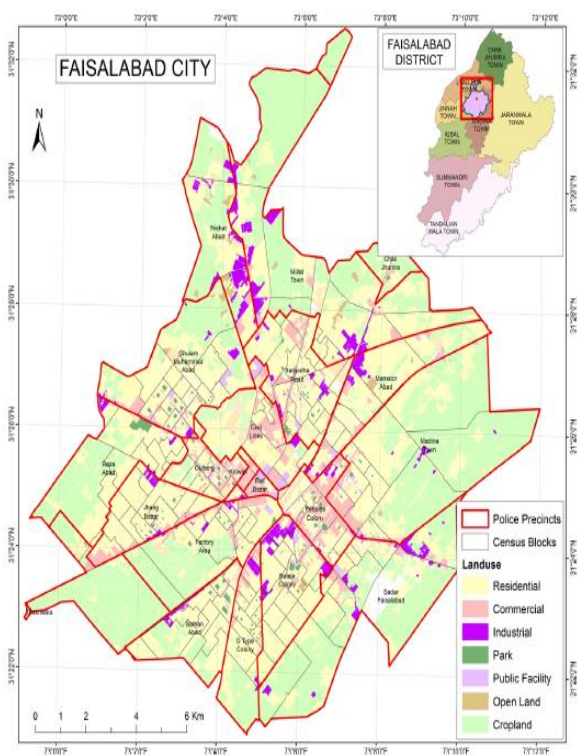

Figure 2: Study area Faisalabad
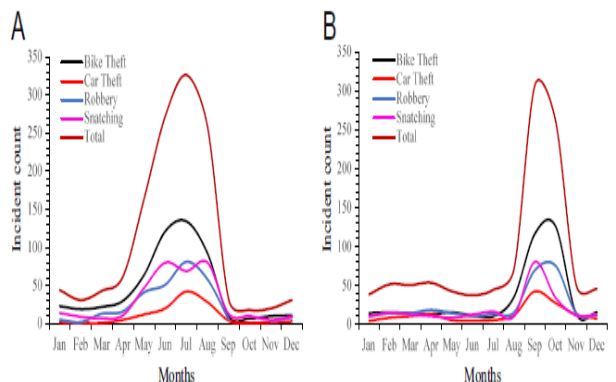

Figure 3: Crime incident 2015(a) and 2016

(b)

\begin{tabular}{|c|c|c|c|c|c|c|c|c|c|c|}
\hline \multirow{2}{*}{$\begin{array}{l}\text { Months } \\
\text { January }\end{array}$} & \multicolumn{2}{|c|}{$\begin{array}{l}\text { Bike Theft } \\
2015-2016 \\
\end{array}$} & \multicolumn{2}{|c|}{$\begin{array}{l}\text { Car Thett } \\
\text { 2015-2016 } \\
\end{array}$} & \multicolumn{2}{|c|}{$\begin{array}{l}\text { Robbery } \\
\quad 2015-2016 \\
\end{array}$} & \multicolumn{2}{|c|}{$\begin{array}{l}\text { Snatching } \\
\quad 2015 \text {-2016 } \\
\end{array}$} & \multirow{2}{*}{$\begin{array}{l}\text { Total } \\
72\end{array}$} & \multirow{2}{*}{$\frac{\% \text { age }}{3.50}$} \\
\hline & 23 & 14 & 2 & 4 & 5 & 10 & 14 & 0 & & \\
\hline February & 19 & 15 & 1 & 0 & 2 & 4 & - & 0 & 50 & 2.43 \\
\hline March & 22 & 4 & 1 & 0 & 13 & 4 & 7 & 0 & 51 & 2.48 \\
\hline April & 30 & 3 & 5 & 0 & 16 & 8 & 11 & 0 & 73 & 3.55 \\
\hline May & 64 & 5 & 12 & 0 & 41 & 4 & 47 & 0 & 173 & 8.40 \\
\hline June & 121 & 1 & 20 & 2 & 51 & 0 & 80 & 2 & 277 & 13.45 \\
\hline July & 134 & 10 & 42 & 2 & 81 & 3 & 69 & 6 & 347 & 16.85 \\
\hline August & 92 & 35 & 28 & 11 & 58 & 15 & 80 & 10 & 329 & 15.98 \\
\hline September & 10 & 116 & 4 & 42 & 5 & 69 & 13 & 80 & 339 & 16.46 \\
\hline October & 7 & 126 & 1 & 27 & 0 & 75 & 10 & 34 & 280 & 13.60 \\
\hline November & 10 & 3 & 2 & 0 & 3 & 4 & 5 & 1 & 28 & 1.36 \\
\hline December & 11 & 5 & 3 & 2 & 8 & 1 & 9 & 1 & 40 & 1.94 \\
\hline rotal & 543 & 337 & 121 & 90 & 283 & 197 & 354 & 134 & 2059 & 100 \\
\hline age & 41.74 & 44.46 & 9.30 & 11.87 & 21.75 & 25.99 & 27.21 & 17.68 & $100 \%$ & \\
\hline
\end{tabular}




\section{Mapping of Police station}
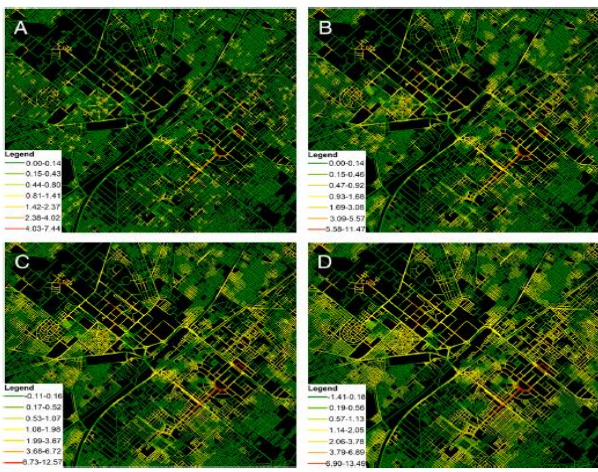

Figure 4: Police Stations and there boundaries (a) $100 \mathrm{~m}$ (b) $200 \mathrm{~m}$ (c) $300 \mathrm{~m}$ (d) $400 \mathrm{~m}$

\section{Conclusion}

Forecast about crime is a tall order; we are not on final stage where we define specific events by a special offender at specific movement in the crime. Using GIS into law enforcement has been an important dramatic for crime analyst and criminal justice researchers [28].To keep crime analysis and decision-making, we need to recognize the complex (spatial) clustering (block) analysis. Maps provide crime analyst graphics representation of crime-related problems. Perceiving where and why crimes occur, can improve the struggle to fight for crime.

Using good management techniques we can reduce crime rates. We need to follow new technology in the 21 st century to prohibit crime [20]. Eventually, mapping and GIS support regional and complicated oriented policing GIS and Mapping can show the comprehensive correlation between the crime, the victim and the offenders. Some important facts of GIS and Crime mapping are: showing the probability and people changes, help in resourcing allocation, combining data from the government resources and community, providing effective communication tools.

Whatever approaches makes sense for you, applying and studying GIS into law and defense is a twice successful choice [21]. As you advance, your own career should make important addition for social freedom and order. Think of it as two benefits for one effort.

\section{ACKNOWLEDGMENT}

We authors acknowledge with thanks the assistance rendered by Dr. Javed Anjum Sheikh, University of Lahore, Gujrat Campus for providing crucial insight during the course of the research work which greatly improved the manuscript.

\section{REFERENCES}

[1] Y. Bello et al., "Principal Component Analysis of Crime Victimizations in Katsina Senatorial Zone", International Journal of Science and Technology, vol. 3, no. 4, pp. 192- 202, 2014.

[2] P. Yar and J. Nasir, "GIS Based Spatial and Temporal Analysis of Crimes, a Case Study of Mardan City, Pakistan", International Journal of Geosciences, vol. 7, no. 19, pp. 325- 334, 2016.

[3] T.F. Balogun et al., "Crime Mapping in Nigeria using GIS" , Journal of Geographic Information System, vol. 6, no. 5, pp. 453- 466, 2014.

[4] S.M. Ansari and Dr. K.V. Kale, "Methods of Crime Analysis using GIS", International Journal of Scientific and Engineering Research, vol. 5, no. 12, pp. 1330- 1336, 2014.

[5] U.S. Usman, "The Role of Geographic Information System (GIS) in Effective Control of Terrorism in Nigeria", International Journal of Economics, Commerce and Management, vol. 3, no. 4, pp. 1- 9, 2015.

[6] 2016. [Online]. Available: http://us.corwin.com/sites/default/files/u pm-

binaries/6244_Chapter_4_Boba_Final_P DF_3.pdf. [Accessed: 23- Nov- 2016].

[7] Crimemapping.info, 2016. [Online]. Available: http://crimemapping.info/wpcontent/uploads/2015/07/CMN3PDFv4.p df. [Accessed: 23- Nov- 2016]. 
[8] Esri.com, 2016. [Online]. Available: http://www.esri.com/software/arcgis/arc gisonline. [Accessed: 11- oct- 2016].

[9] "Crime Mapping and spatial Analysis", Itc.nl. [Online]. Available: http://www.itc.nl/library/papers_2003/m sc/gfm/ahmadi.pdf. [Accessed: 27- Nov2016].

[10] F. Fajemirokun et al., "A GIS Approach to Crime Mapping and Management in Nigeria: A Case Study of Victoria Island Lagos", Nigeria.

[11] Crime Mapping \& Analysis News", Crime Mapping and Analysis News, 2016. [Online]. Available: https://crimemapping.info/wpcontent/uploads/2016/12/CMAN-Issue5.pdf. [Accessed: 17- Oct- 2016].

[12] N. Levine, "Crime Mapping and the Crimestat Program", Wiley Online Library. [Online]. Available: http://onlinelibrary.wiley.com/doi/10.11 11/j.0016 7363.2005.00673.x/full. [Accessed: 22- Nov- 2016].

[13] A. Ahmed \& R. Saliha, "spatiotemporal pattern of crime using GIS approach in Dala L.G.A. Kano state, Nigeria”, American Journal of Engineering Research, vol. 2, no. 3, 2013

[14] G.O. Igbaekemen \& S.U. Umar, "A Purview into the historical Development of

Terrorism

in Nigeria”, Journal of Developing country Studies, vol. 4, no. 14, 2014

[15] O. James, "GIS and Crime Management in Nigeria", International Journal of Sociology, Management and Security Studies, Maiden Edition, Kano, Nigeria, 2013

[16] F. Onu, "Corrupt Practices in Nigeria Society", A Search For Causes and Remedies. IJMSSS, Kano State, Nigeria, vol. 1 , no. 1,2014

[17] J. Shekwo, "Juvenile Delinquency in Mararaba, Karu L.G.A. of Nasarawa
State, Nigeria", International Journal of Sociology, Management \& Security Studies, Maiden Edition, Kano, Nigeria, 2013

[18] S.A. Yelwa \& Y. Bello, "Complimenting GIS and Cluster Analysis in Assessing Property Crime in Katsina State, Nigeria", American International Journal of Contemporary Research, Vol. 2, no. 7, 2012

[19] S. Pires"crime mapping and analyses news",International Journal of Science and Technology, vol. 4, no. 5, pp. 1-30 , 2012.

[20] M.A.P chamikara.,"GIS in crime analysis", International Journal of Science and Technology, vol. 3, no. 6, pp. $3,2014$.

[21] J. Bueermann.,"Crime analysis",Journal of Environment and Earth Science, vol. 2, no. 3, pp. 1-6, 2012.

[22] M.brokmaan et al.,"Crime Mapping and Analysis in the Dansoman Police Subdivision", Journal of Environment and Earth Science, vol. 4, no. 3, pp. 111,2014 .

[23] C.D.J beaty.,"GIS for Crime Analysis, Law Enforcement, GIS and Public Safety", Journal of Environment and Earth Science, vol. 4, no. 3, pp. 117,2012.

[24] T.Fransic et al.,"Crime Mapping in Nigeria",scrip.org.[Online].Available: http://www.scirp.org/journal/PaperInfor mation.aspx?PaperID=50296. [Accessed: 20- Nov- 2016].

[25] j.corso et al.," Toward Predictive Crime Analysis via Social Media, Big Data, and GIS", Journal of Environment and Earth Science, vol. 2, no. 3, pp. 1-6, 2015.

[26] S.Muhammad et al.," Mapping and Analysis of Crime in Aurangabad City using GIS", IOSR Journal of Computer Engineering (IOSR-JCE), vol. 2, no. 4, pp. 67-76, 2014. 
[27] F.Wang.,"Why Police and Policing need GIS",Journal of Environment and Earth Science, vol. 2, no. 4, pp. 67-76, 2012.

[28] T.Balogan et al.," Crime Mapping in Nigeria Using GIS",Journal of Geographic Information System, vol.6, no. 4, pp. 453-466, 2014.

[29] J. H. Davis and J. R. Cogdell,"Crime in GIS,” Elect. Eng. Res. Lab., Univ. Texas, Austin, Tech. Memo. NGL-006-69-3, Nov. 15, 1987.

[30] R. E. Haskell and C. T. Case, "Hotspot in Crime mapping," USAF Cambridge Res. Labs., Cambridge, MA, Rep. ARCRL66-234 (II), 1994, vol. 2.

[31] P. Diament and W. L. Lupatkin,"GIS in Crime Mapping,” Dept. Elect. Eng., New York, Sci. Rep. 85, Aug. 1991

[32] Crime with GIS, 3rd ed., Western Electric Co.,Winston-Salem, NC, 2010, pp. 4460.

[33] GIS in Crime mapping., $1^{\text {st }}$ ed.,Spencer Chainey, Jerry Ratcliffe., 2010,pp.1-421.

[34] "Hartsfield-Jackson Atlanta International Airport," [Online]. Available: Http://Www.Esri.Com/Software/Arcgis/ Arcgisonline. Accessed: Nov. 25, 2016. 